\title{
Метрологическая экспертиза технической документации как один из этапов повышения качества
}

\author{
С. Ведерников ${ }^{1}$
}

УДК 389.008.4 | ВАК 05.11.15

\author{
В условиях рыночной экономики производимая продукция (изделия) должна \\ отличаться высокими показателями качества, а процесс производства - \\ максимально оптимизирован и эффективен для снижения экономических \\ затрат.
}

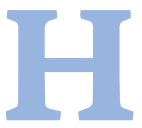

екоторые руководители предприятий и организаций не уделяют должного внимания процессу метрологической экспертизы (МЭ) документации ввиду отсутствия явной выгоды от ее проведения. Причиной этого является отсутствие понимания, что МЭ позволяет:

- повысить качество производства и уменьшить количество брака;

- оптимизировать процессы производства, испытаний, эксплуатации и ремонта изделий;

- снизить экономические затраты и издержки (в том числе исключив скрытые потери).

По статистике, более 50\% продукции неудовлетворительного качества связано с нарушением метрологических норм и правил. При этом значительная доля нарушений метрологических требований приходится на нормативную и другую техническую документацию, особенно на стадиях разработки технического задания и эскизного проекта. Устранение метрологических ошибок на стадии разработки документации проще, чем на стадии производства, испытаний и эксплуатации. Такой подход определяет максимальный экономический эффект от экспертизы. Проведение Мэ на последующих стадиях разработки ведет к материальным потерям не только за счет снижения объема и точности информации, но и за счет потери материальных средств и времени, необходимых для устранения обнаруженных недостатков в области метрологического обеспечения

Следует отметить, что непроведение метрологической экспертизы технической документации является причиной:

- неправильного выбора параметров, подлежащих измерению (контролируемых параметров);

- необоснованного выбора норм точности измерений;

АО «ТЕСТПРИБОР», эксперт-метролог
- неправильного выбора метода и средств измерений для процесса разработки, изготовления, испытания, контроля продукции.

Все это может сказаться на качестве, себестоимости продукции, а в некоторых случаях привести к более тяжелым последствиям.

Рассмотрим конкретный пример решения задачи метрологической экспертизы для повышения качества выпускаемой продукции и уменьшения количества брака.

Брак - продукция с дефектом, несоответствующая установленным требованиям. Требования к признакам и параметрам продукции, качественно и количественно характеризующим любые ее свойства и состояние, устанавливаются в разделе «Технические требования" технических условий на продукцию, а методы подтверждения соответствия продукции требованиям излагаются в разделе «Методы контроля». Требования должны обеспечивать заданные эксплуатационные показатели качества продукции с учетом погрешности методов измерения. В случае ее отсутствия устанавливаются некорректные приемочные уровни контролируемых параметров продукции, и, как следствие, увеличивается доля продукции с необнаруженными отказами.

Для более детального рассмотрения создадим графическую модель контролируемого параметра X (рис. 1). Погрешность его измерений определяется только погрешностью средства измерения. На рис. 1 обозначена область допустимых значений контролируемого параметра, при котором изделие будет работоспособно и правильно функционировать.

В результате измерительного контроля, проводимого по методике технических условий, измеренное значение $X_{\text {изм }}$ по показаниям средства измерения должно удовлетворять условию $\mathrm{X}_{\mathrm{H}} \leq \mathrm{X}_{\text {изм }} \leq \mathrm{X}_{\mathrm{B}}$. При этом из-за наличия погрешности $\pm \Delta_{\text {си }}$ средства измерения, изделия могут быть признаны ошибочно "годными» (необнаруженный отказ). В этом случае значения параметра лежат в интервале $X_{\mathrm{H}}-\Delta_{\text {си }} \leq X_{\text {изм }} \leq X_{\text {в }}+\Delta_{\text {Си }}$, представленном на рис. 2. 


\section{АТТЕСТАШИЯ}

\section{испытательного оборудования}

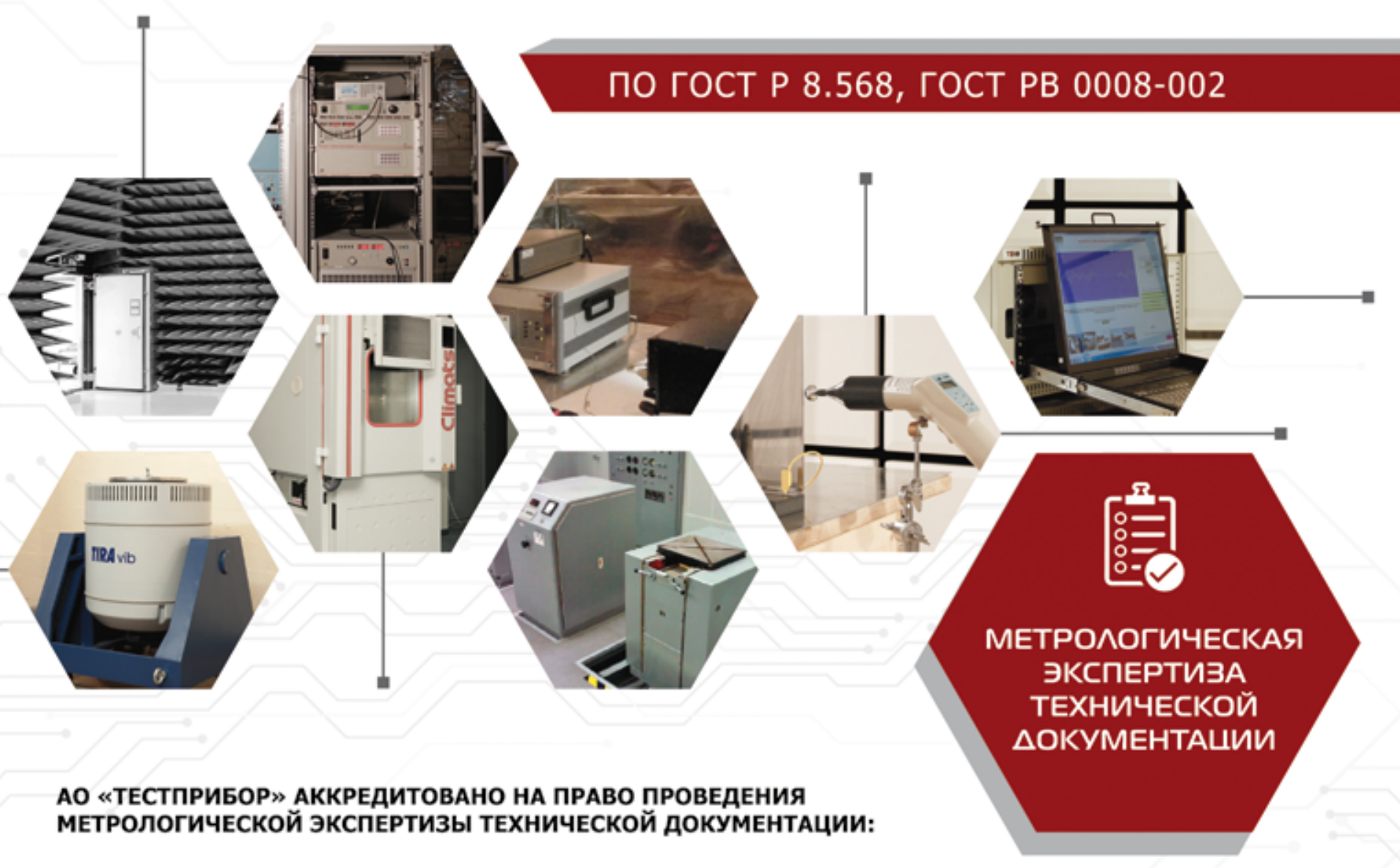

Проектной, конструкторской, технологической, эксплуатационной документации, нормативных и других документов, в том числе по программному обеспечению, применяемых при разработке, производстве, испытаниях и эксплуатации изделий и другой продукции, в том числе оборонной, и в сфере услуг.

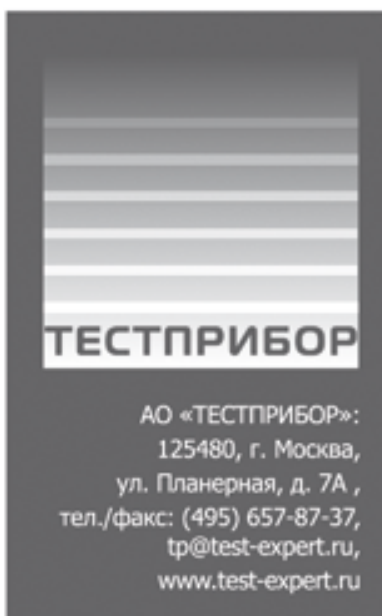

АО «ТЕСтПРИБОР» осуществляет аттестацию испытательного оборудования в соответствии с областью аккредитации:

- 6езэховые экранированные камеры

- акустические камеры

- климатические камеры (термогигрокамеры)

- камеры повышенного давления

- камеры пониженного атмосферного давления

- стенды вибрационные
- стенды ударные

- центрифуги

- камеры статической и динамической пыли

- камеры соляного тумана

- камеры дождя

- испытательное оборудование (комплексы) для воспроизведения электростатических разрядов
- специальное испытательное оборудование, испытательные комплексы

- испытательное оборудование (комплексы) для испытаний на воздействие электрических и радиотехнических величин 
Таблица 1. Эффективность проведения метрологической экспертизы

Задачи метрологической экспертизы

Оценка полноты и четкости формулирования технических требований

Оценка обоснованности состава измеряемых и контролируемых параметров

Оценка обоснованности требований к точности определения параметров изделия

Оценка контролепригодности изделия при испытаниях, эксплуатации и ремонте

Оценка полноты, правильности выбора и применения СИ
Польза проведения (выгода)

Корректировка выражения требований, которое исключает возможность различного толкования

Обеспечение оптимального качества изделия, снижение затрат в процессе измерений и технологических потерь, а также затраты на контроль

Точность измерений параметра является экономически оптимальной при достижении максимального качества изделия

Совершенствование производственного процесса, повышение качества изделий, снижение времени контроля параметров

Оптимизирование номенклатуры СИ, обеспечение минимальной трудоемкости и себестоимости контрольных операций для получения требуемой точности измерений

Оценка полноты и правильности применения стандартизированных и (или) аттестованных методик измерений

Исключение ошибок и некорректных измерений контролируемых параметров

Повышение качества изделия, исключение ложного и необнаруженного отказов ности измерений и алгоритму обработки результатов измерений

\section{Анализ использования вычислительной $\quad$ Ускорение процесса производства и контроля} техники в измерительных операциях

Проверка правильности применения терминов и определений, наименований и обозначений единиц величин
Снижение затрат на корректировку документации в производственных условиях
Результат измерения контролируемого параметра должен определяться выражением

$$
X_{\text {изм }}=X_{\text {Си }} \pm \triangle_{\text {Си, }}
$$

где: $X_{\text {си }}-$ показания средства измерения

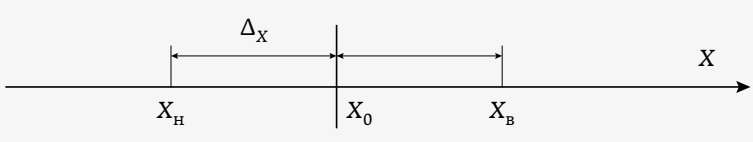

$X$ - контролируемый параметр

$X_{0}$ - номинальное значение контролируемого параметра

$\Delta_{\mathbf{X}}$ - область допустимых отклонений контролируемого параметра

$X_{\mathrm{H}}$ - нижнее допустимое значение контролируемого параметра

$X_{\mathrm{B}}$ - верхнее допустимое значение контролируемого параметра

Рис. 1. Графическая модель контролируемого параметра $X$
Рекомендации по назначению приемочного уровня контролируемого параметра $\Delta_{\Pi}$ с учетом погрешности его измерений:

1. На параметр изделия задан допуск $\triangle_{X}$ и номинальное значение $X_{0}$. Как правило, для измерений параметра выбирают средство измерения с коэффициентом точности $\mathrm{K}_{\mathrm{T}} \geq 3$.

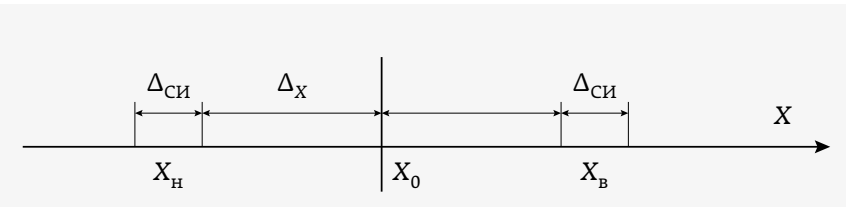

$\Delta_{\text {си }}$ - пределы допускаемой погрешности средства измерения (погрешность)

Рис. 2. Графическая модель с добавлением пределов допускаемой погрешности средства измерения 
Чтобы исключить необнаруженный отказ, следует назначить приемочный уровень контролируемого параметра согласно выражению $X_{\mathrm{H}}+\Delta_{\text {си }} \leq \Delta_{\Pi} \leq X_{\mathrm{B}}-\Delta_{\text {си }}$ (рис. 3).

2. В технических требованиях задано значение параметра в виде "не более $X_{0}$ " и допустимая погрешность его измерений $\triangle_{\text {доп }}$. Для такого случая целесообразно выбрать средство измерения, пределы допускаемой погрешности которого $\Delta_{\text {си }} \leq \Delta_{\text {доп }}$. Назначить приемочный уровень контролируемого параметра согласно выражению $\triangle_{\Pi} \leq X_{0}-\Delta_{\text {си. }}$.

3. В технических требованиях задано значение параметра $X_{0}$, но отсутствует допуск на параметр $\Delta_{\mathrm{X}}$ и допустимая погрешность измерений $\triangle_{\text {доп }}$. Такая постановка не редкость и требует доработки документации. Согласно нормативным документам следует установить допуск на контролируемый параметр и исходя из него подобрать подходящее средство измерения. Назначить приемочный уровень контролируемого параметра согласно выражению $X_{\mathrm{H}}+\Delta_{\text {си }} \leq \Delta_{\mathrm{n}} \leq X_{\mathrm{B}}-\Delta_{\text {Си }}$.

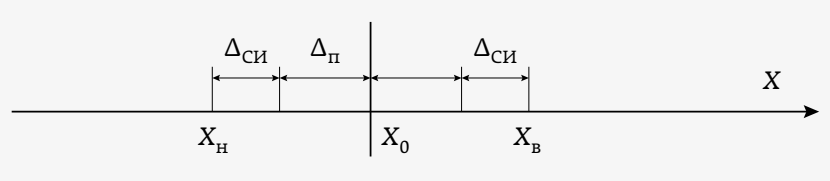

$\Delta_{\text {п }}$ - приемочный уровень контролируемого параметра

Рис. 3. Графическая модель с назначенным приемочным уровнем контролируемого параметра

Представленные выше рекомендации помогают исключить необнаруженный отказ и повысить качество изделий. Важность проведения метрологической экспертизы для обеспечения единства измерений давно доказана метрологической практикой. Метрологическая экспертиза технической документации играет ведущую роль в обеспечении качества на всех этапах жизненного цикла продукции.

\section{НОВЫЕ КНИГИ ИЗДАТЕЛЬСТВА "ТЕХНОСФЕРА"}

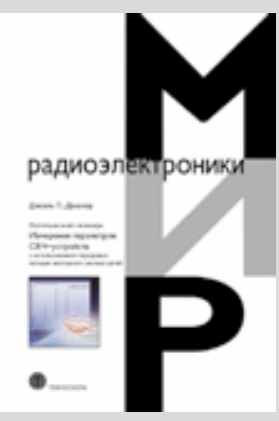

Цена 1600 руб.

\section{НАСТОЛЬНАЯ КНИГА ИНЖЕНЕРА ИЗМЕРЕНИЯ ПАРАМЕТРОВ СВЧ-УСТРОЙСТВ С ИСПОЛЬЗОВАНИЕМ ПЕРЕДОВЫХ МЕТОДИК ВЕКТОРНОГО АНАЛИЗА ЦЕПЕЙ Дансмор Джоэль П. Издание осуществлено при поддержке Keysight Technologies}

За последнюю четверть века в радиоэлектронной промышленности произошли революционные изменения, и немаловажную роль в этих переменах сыграла техника сверхвысоких частот. Успех разработки устройств СВч-диапазона непосредственно связан с качеством и широтой возможностей по анализу их параметров. Автор книги - инженер-разработчик с 30-летним стажем - работал над широчайшим кругом измерительных задач в Свчдиапазоне: от компонентов сотового телефона до спутниковых мультиплексоров.

Написанная им книга - это совокупность основ и передового опыта, теории и практики, в центре внимания которой - измерения активных и пассивных устройств с использованием новейших методик векторного анализа цепей, в том числе конфигурации современных векторных анализаторов цепей, методики их калибровки, подходы к анализу полученных результатов измерений, неопределенностей и составляющих систематической погрешности. Значительная часть книги посвящена описанию наглядных практических примеров измерений параметров таких устройств, как кабели и соединители, линии передачи, фильтры, направленные ответвители, усилители и смесители, балансные устройства и пр.

Книга станет прекрасным практическим руководством для инженеров-метрологов и разработчиков ВЧ-/СВЧ-устройств. 